\title{
Control of a Three-Port DC-DC Converter for Grid Connected PV-Battery Applications
}

\author{
Karstensen, Peter Iwer Hoedt; Tomas Manez, Kevin; Zhang, Zhe
}

Published in:

Proceedings of 3rd International Conference on Intelligent Green Building and Smart Grid

Link to article, DOI:

10.1109/IGBSG.2018.8393561

Publication date:

2018

Document Version

Peer reviewed version

Link back to DTU Orbit

Citation (APA):

Karstensen, P. I. H., Tomas Manez, K., \& Zhang, Z. (2018). Control of a Three-Port DC-DC Converter for Grid Connected PV-Battery Applications. In Proceedings of 3rd International Conference on Intelligent Green Building and Smart Grid IEEE. https://doi.org/10.1109/IGBSG.2018.8393561

\section{General rights}

Copyright and moral rights for the publications made accessible in the public portal are retained by the authors and/or other copyright owners and it is a condition of accessing publications that users recognise and abide by the legal requirements associated with these rights.

- Users may download and print one copy of any publication from the public portal for the purpose of private study or research.

- You may not further distribute the material or use it for any profit-making activity or commercial gain

- You may freely distribute the URL identifying the publication in the public portal 


\title{
Control of a Three-Port DC-DC Converter for Grid Connected PV-Battery Applications
}

\author{
Peter Iwer Hoedt Karstensen, Kevin Tomas Manez, Zhe Zhang \\ Department of Electrical Engineering \\ Technical University of Denmark \\ Kgs. Lyngby, Denmark \\ Email: pekadk94@gmail.com
}

\begin{abstract}
A control strategy for an energy management system (EMS) of a household nanogrid is presented in this paper. The proposed EMS is based on a state diagram. A three port converter (TPC) with direct storage capability is chosen and the states together with the state transitions are defined. The state diagram signals to two algorithms of which one calculates the battery current reference and the other allows the photovoltaic (PV) system to operate at the maximum power point (MPP) at all times. An extensive model has been implemented in MATLAB/Simulink using generic models to test the proposed control method. Results show a system which at all times follows a specified power exchange with the grid with a overshoot in power of $500 \mathrm{~W}$ and worst case settling time of $500 \mathrm{~ms}$.
\end{abstract}

Keywords-EMS, PV-battery application, state diagram, three port converter,

\section{INTRODUCTION}

In the last years there is a growing interest in distributed generation systems (DGS) in the form of PV systems connected to households. Since the power generation of PV systems are dependent on the weather, a constant output power cannot be expected. The power generation reliability is playing a vital role for distribution companies and they therefore seek reliable power sources and consumers. By installing energy storage systems (ESS) in conjunction with PV systems, the shortcomings that power intermittency causes to the grid can be solved [1]. To regulate and accommodate the different voltage levels of PV modules and ESS, DC-DC converters have to be introduced into the systems. The general structure of such systems is depicted in Fig. 1.

The control of the whole system previously described, can be divided in two levels defined as top-level and bottom-level. The top-level refers to the energy management system (EMS), which controls the power flow in order to make efficient use of the power produced and reduce the power consumed from the electrical grid. In addition, the EMS has to ensure that the PV system always operate at the maximum power and that the ESS power flow is carefully controlled to prolong its lifetime. The bottom-level refers to the regulation of the DC-DC converters from the references provided by the EMS.

In this paper, a control system, with focus on the EMS, for the topology shown in Fig. 2 and presented in [2] is proposed. The TPC has direct storage capability, meaning that only one power conversion stage is needed between the PV system and the ESS, resulting in a more efficient converter and enabling a local EMS. Direct energy storage capability implies that two

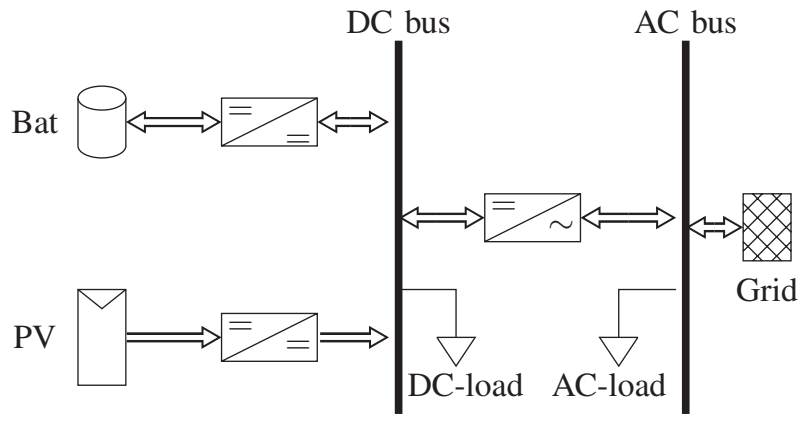

Fig. 1: General structure of nano DC-grids

DC-DC conversion units directly connected to the PV and with different outputs, have to operate simultaneously. This, together with the multiple operation modes available, implies a challenging design of the control system. This also puts the TPC under certain transition conditions. An EMS based on a state diagram is developed for the control of the TPC, which makes transitions between the different operating modes easily described and incorporated in the EMS.

In Section II a short recap of the converter and its operating modes will be given, followed by Section III in which the state-diagram control strategy will be explained and the states and transition condition will be identified. In Section IV the design and implementation in Simulink will be explained in detail. In Section $\mathrm{V}$ the simulation results will be presented and discussed. Finally a conclusion of the control is given in Section VI.

\section{CONVERTER}

The circuit topology of the TPC is presented in Fig. 2. The TPC is connected to the electrical grid through an H-Bridge single-phase inverter and a LCL filter. The ESS used in this work is a lithium-ion battery.

The TPC can be described with simple buck and boost converters depending on the active switches. A short summary of the different operation modes is given in Table I.

\section{EMS CONTROL STRATEGY}

The power considered in this paper is the power generated by the PV system, $P_{P V}$, the power absorbed by the DCload and AC-load, $P_{D C}$ and $P_{A C}$, and the power absorbed 
TABLE I: Converter operation modes

\begin{tabular}{llll}
\hline State & Operation & Active switches & Bodydiode \\
\hline 0(Idle) & No operation & None & \\
1 & Boost(PV - > DCBus) & $Q_{1}$ & $Q_{5}$ \\
2 & Buck(PV - > Bat) & $Q_{2}$ & $Q_{3}$ \\
3 & Boost(PV - > DCBus) \& Buck(PV -> Bat) & $Q_{1}, Q_{2}$ & $Q_{5}, Q_{3}$ \\
4 & Boost(Bat - > DCBus) & $Q_{3}$ & $Q_{4}$ \\
5 & Boost(Bat - > DCBus) \& Boost(PV - > DCBus) & $Q_{1}, Q_{3}$ & $Q_{5}, Q_{4}$ \\
6 & Buck(DCBus - > Bat) & $Q_{4}$ & $Q_{3}$ \\
7 & Buck(PV - > Bat) \& Buck(DCBus - > PV) & $Q_{5}, Q_{2}$ & $Q_{1}, Q_{3}$ \\
\hline
\end{tabular}

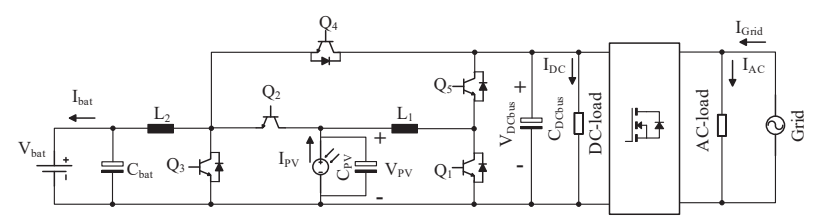

Fig. 2: The three port converter

or delivered by the grid and the ESS, $P_{G r i d}$ and $P_{b a t} . P_{P V}$, $P_{D C}$ and $P_{A C}$ can be zero or positive. $P_{G r i d}$ and $P_{b a t}$ can be negative, zero or positive. The power flow of the converter is expressed through (1).

$$
P_{b a t}+P_{G r i d}+P_{P V}+P_{D C}+P_{A C}=0
$$

From (1) it can also be inferred that there is a need of nine measurement points. These are the voltages and currents highlighted in Fig. 2. The voltage across and current through the battery would be delivered by a battery management system (BMS) which also informs about the state of charge (SoC) of the battery.

The EMS and power flow control is implemented with a state diagram. The proposed system contains multiple operation modes and operation transitions which can be accurately defined with a state diagram. The EMS needs to fulfill these requirements which among other also are operation conditions:

- To a great extent be able to deliver or absorb a power specified by the grid operator

- Always ensure that the PV is operated at MPP

- Ensure safely charging and discharging of the battery and consider the SoC of the battery

\section{A. States and transition conditions}

The states in the state-diagram are the different operating modes of the proposed TPC as shown in Table I.

Considering (1) the needed transition conditions for the power can be inferred. In this case it is $P_{P V}, P_{G r i d}, P_{D C}$ and $P_{A C}$ and the relationship between them that determine the transition condition as shown in Table II. $P_{P V}, P_{D C}$ and $P_{A C}$ are measured quantities but $P_{\text {Grid }}$ needs to be the power specified by the grid operator when calculating the transition conditions hence making it the reference which is followed by the EMS. This quantity is denoted as $P_{\text {GridN }}$. The relationship between the different power needs to be calculated
TABLE II: Transition conditions

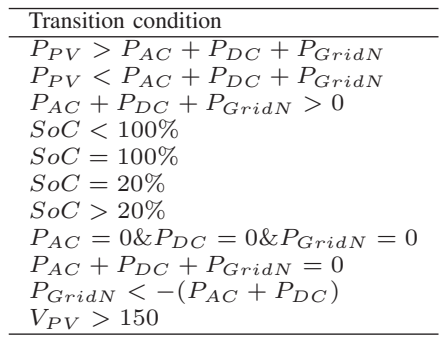

corresponding to the active state to check whether a transition needs to occur.

In some cases the power delivered or supplied by the battery needs to be considered. One case would be a transition from state 5 to state 3 or vice versa. An immediate transition between these two states would mean a change of direction of the battery current resulting in transients. By decreasing the current to zero before the transition, transients are avoided. This applies to all transitions between states that either changes the direction of currents or reduces the operation from two active converters to one as is the case when going from state 3 to state 2 .

In order to make the battery supply or absorb the surplus power it is needed to make an algorithm which calculates the current reference for the battery. Therefor, two control loops have to be implemented. The first one which controls the charging and discharging power for the battery and a second one which carries out the MPPT of the PV system.

\section{B. Converter dynamics}

As can be seen in table I the converter can in each operation mode either be described with a regular buck or boost converter. The small signal model of each operation mode can be derived using the state space averaging approach described in [3]. The operation modes defined as state 3, 5 and 7 stand out since the converter in those operation modes is required to have two control loops active. Since the PV system is between the two conversion stages in state 7, its small signal variation can be seen as a disturbance to the bus small signal variation and vice versa. In this operation mode the MPPT will control $Q_{2}$ and the battery algorithm will control switch $Q_{5}$. This means that effectively there exist an outer and inner control loop in this operation mode. Since the buck converter consisting of $Q_{5}$ is connected to the PV modules terminals this buck converts control must be faster than the changes at the PV modules terminal.

The control of the single phase inverter is implemented as described in [4].

\section{DESIGN OF THE EMS}

In this section the design of the EMS and state diagram will be explained in detail where (1) and the $\mathrm{SoC}$ of the battery are included.

The EMS is built as depicted in Fig. 3. The top-level control is split up in three parts. The state-diagram computes the state 


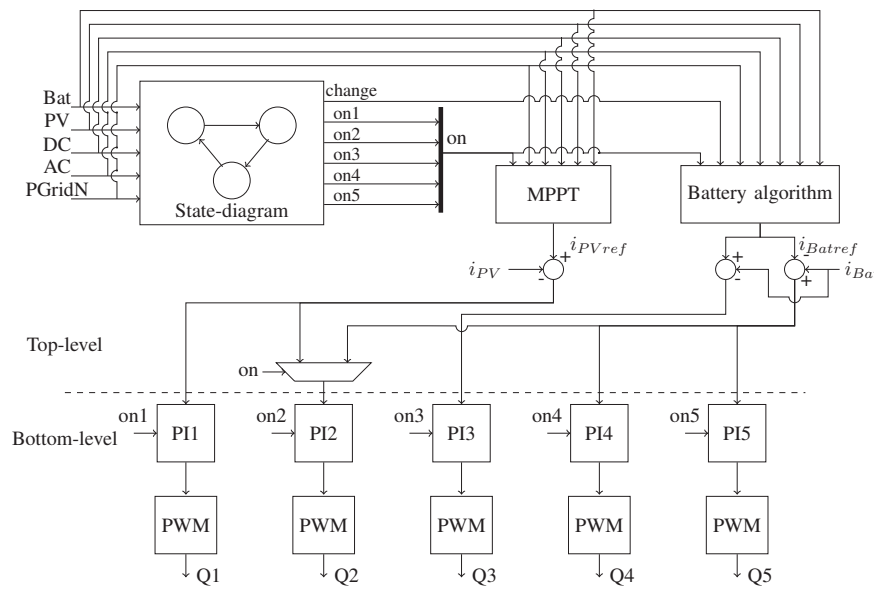

Fig. 3: Depiction of the EMS and its parts

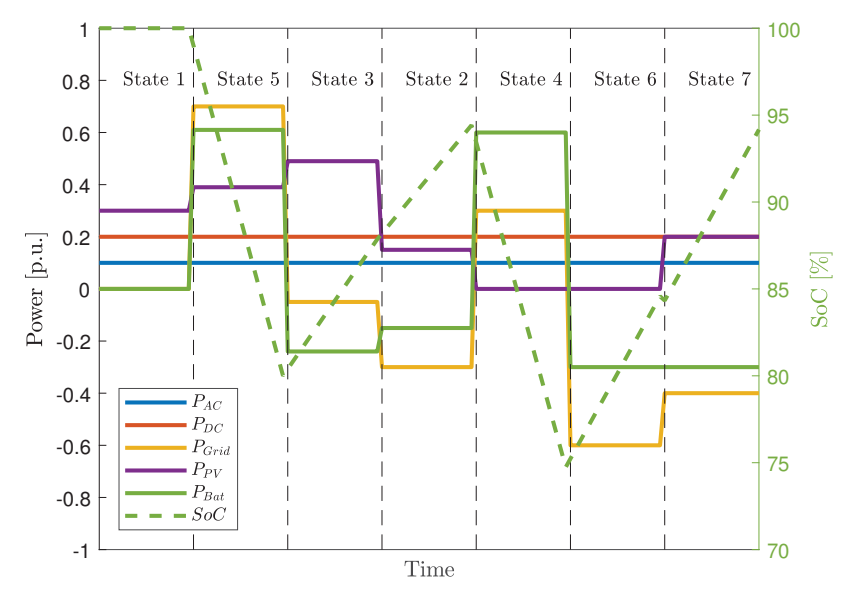

Fig. 4: Example of the state transitions under different conditions

transitions yielding the on/off signals denoted as on 1-5 and in the figure concatenated into one signal denoted on. These are also used to activate their corresponding PI-controllers when they are logical high. Additionally the concatenated onsignal is used as the select in a multiplexer which passes the control signal to $Q_{2}$ 's PI-controller corresponding to the active state. The signal denoted as Bat carries all information about the batteries. Signals $P V, D C, A C$ are the voltages across and currents through the PV system, DC-load and ACload respectively. PGridN is the power specified by the grid operator.

The change-signal is used to override normal operation of the battery algorithm in order for some transition conditions to be performed. This would be the case of a transition from state 3 to state 7 . The algorithm needs to make the battery absorb all the power generated by the PV system before making the transition, thus preventing transients when the transistion happens.

After a transition has occurred the currents and thereby the powers need to settle at the specified references before the next transition is computed. Therefore, the sampling frequency of the MPPT and battery algorithm needs to be higher than the sampling frequency of the state diagram. The sampling frequency of the MPPT and battery algorithm have to be chosen lower than the closed loop control bandwidth.

The battery algorithm uses (1) to calculate the battery current reference. Considering row one in Table II the PV system supplies enough power to cover the demands of the grid operator and the loads. Hence there will be surplus power generated by the PV modules which is stored in the batteries. The surplus power is divided by the voltage of the battery yielding the current reference. The algorithm has a parameter which can tune the current references increment in order to make it slower. This prevents the current reference from increasing too fast and hence minimizing the risk of transients. The MPPT uses a simple perturb and observe algorithm.

The states are described in the following and Fig. 4 illustrates the different power levels in each state. The transitions are ideal and exaggerated in order to demonstrate the transitions. Table I has the states listed. The implemented transition conditions are shown in Table II.

1) State 1 is entered when $\mathrm{SoC}=100 \%$ and power required by the grid and loads can be supplied by the PV system.

2) State 2 is where the loads are supplied by only the grid. In this case the battery $\mathrm{SoC}<100 \%$ and power is available through the PV.

3) State 3 is entered if the battery SoC $<100 \%$ and the PV generates enough power to supply the loads and the power demanded by the grid.

4) State 4 will be entered if there is no solar irradiation, but loads are connected and the grid operator is demanding power.

5) State 5 is entered if the power required by the loads and grid exceed the power generated by the PV. The battery then needs to supply the remaining power.

6) State 6 is entered if the grid operator has surplus power. This surplus power exceeds the power needed by the loads which leaves a residual power and can be stored in the battery. In addition there is no solar irradiation or the residual power mentioned earlier results in a charging current equal to or bigger than the maximum charging current allowed by the battery.

7) State 7 is very similar to state 6 but in this state the residual power mentioned in the former state description is resulting in a smaller charging current than the maximum charging current. This leaves some room for the PV to supply the remaining power such that the resulting charging current reaches the maximum charging current. This means that the PV system may not be operating at the MPP.

\section{Simulation RESUlts}

In order to test the proposed control strategy a comprehensive simulation was constructed. This was done with MATLAB/Simulink using Simscape. To model the PV panels the block PV array was used. The battery model is modeled with the battery block implementing a generic battery model. 
TABLE III: Converter values

\begin{tabular}{|c|c|}
\hline Component & Value \\
\hline$L_{1} \& L_{2}$ & $5 \mathrm{mH}$ \\
\hline$C_{\text {Bat }}$ & $45 \mu F$ \\
\hline$C_{B u s}$ & $3 m F$ \\
\hline$C_{P V}$ & $30 \mu F$ \\
\hline Li-ion battery & $150 V_{\text {nominal }} \& 40 \mathrm{Ah}$ \\
\hline Switching frequency $f_{s}$ & $20 \mathrm{kHz}$ \\
\hline Bus voltage $V_{D C B u s}$ & $400 \mathrm{~V}$ \\
\hline Maximum power & $3500 W$ \\
\hline
\end{tabular}
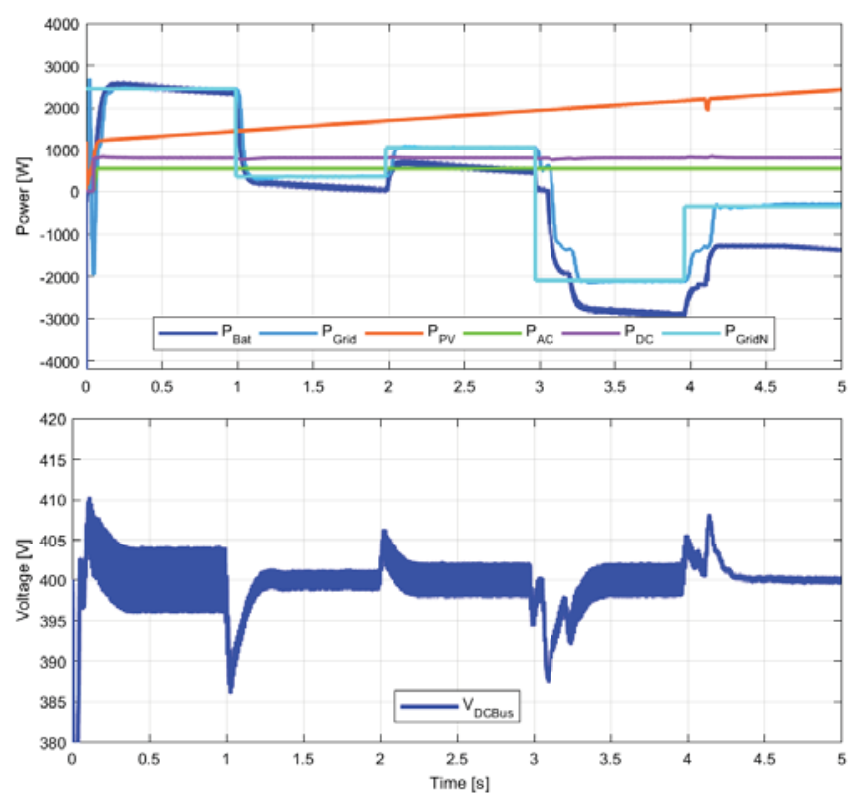

Fig. 5: These result show the powers from (1) when a linear increasing power from the PV systems is applied to the TPC. The second graph shows the DC-bus voltage.

The following results from the simulation will demonstrate the robustness of the system. Additional info about the converter and components are found in table III.

In Fig. 5 the power flow results of the simulations with a linearly increasing solar irradiation and an arbitrary power demand pattern are shown. From the results it can be seen that the actual power exchanged with the grid follows the demand of the grid operator. In these simulation results the worst case transition condition is tested, from state 3 to 7 , which is when the grid operator suddenly changes the power from supplying to absorbing and with great magnitude. The transitions respond with a delay of $500 \mathrm{~ms}$ with regard to the power demand of the grid operator. The battery reference does not change immediately but with a slope. This is done in order to prevent transients and hence helps to keep the DC-bus voltage stable.

In Fig. 6 the simulation result is depicted with a solar radiation pattern increasing and decreasing exponentially in some intervals and with an arbitrary power demand pattern. With the two patterns the EMS undergoes numerous state transitions. In addition loadsteps are performed. The loadsteps result in a deviation from the grid operators demand in less than $100 \mathrm{~ms}$ and in worst case deviates with $500 \mathrm{~W}$. The results show a stable operation throughout the test. The fluctuation
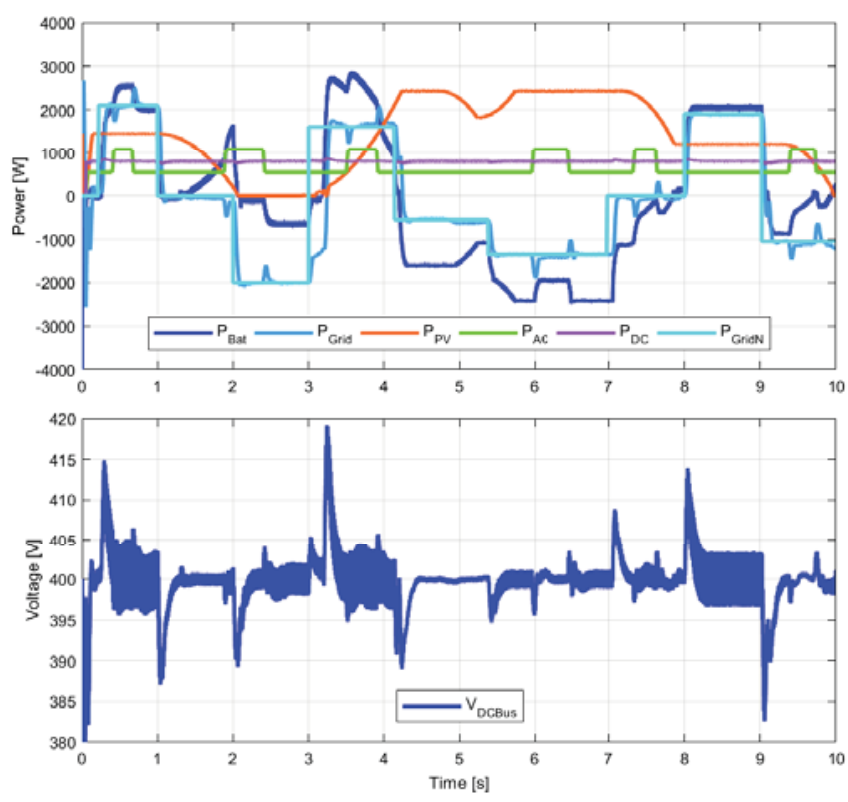

Fig. 6: The first graph shows the powers from (1) following a power demand pattern from the grid operator. The second graph shows the DC-bus voltage.

in voltage coincide with the steps in the battery current and can be minimized with the tuneable increment in the battery reference.

\section{CONCLUSiON}

It has been demonstrated that the proposed TPC can be controlled with a state diagram. The TPC's operating modes were identified as the states and numerous transition condition were implemented. Besides the state diagram, a battery algorithm and a MPPT comprises the EMS of the proposed TPC. Testing the proposed EMS in MATLAB/Simulink yielded results which show that the EMS is able to follow the demand specified by a grid operator. The response of the system with respect to the grid is faster than $500 \mathrm{~ms}$. In addition transients due to transitions between states can be minimized by use of the battery algorithm. Future work would be to include more inputs to demonstrate the state diagram controls versatility.

\section{REFERENCES}

[1] D. Kumar, F. Zare, and A. Ghosh, "Dc microgrid technology: System architectures, ac grid interfaces, grounding schemes, power quality, communication networks, applications, and standardizations aspects," IEEE Access, vol. 5, pp. 12230-12 256, 2017.

[2] K. Tomas-Manez, A. Anthon, Z. Zhang, Z. Ouyang, and T. Franke, "High efficiency non-isolated three port dc-dc converter for pv-battery systems," in 2016 IEEE 8th International Power Electronics and Motion Control Conference (IPEMC-ECCE Asia), May 2016, pp. 1806-1812.

[3] R. W. Erickson and D. Maksimović, Fundamentals Of Power Electronics, 6th ed. Dordrecht: Kluwer Academic Publishers Group, 2004.

[4] R. Teodorescu, M. Liserre, and P. Rodríguez, Grid Converters for Photovoltaic and Wind Power Systems, 1st ed. Chichester: Wiley, 2011. 